\title{
Learning Idioms Through the Multimodal Approach
}

\author{
Byron Rene Pintado ${ }^{*} \quad$ Tammy Fajardo ${ }^{2}$ \\ 1. Language Department, University of Cuenca, Ecuador \\ 2. Philosophy Faculty, University of Cuenca, Ecuador \\ * E-mail of the corresponding author: byron.pintadop@ucuenca.edu.ec
}

\begin{abstract}
The present quasi-experimental study investigated the effects of using the Multimodal Approach for teaching English idioms to 24 A2 EFL Ecuadorian learners majoring in Math, Social Work, Law, Journalism, Physical Education, Philosophy, and Engineering. All the participants were students of the University of Cuenca, Ecuador and whose mother language is Spanish. In order to collect the necessary data, a quantitative method was used. Data was collected by means of a pretest and posttest. The analysis and discussion of the quantitative data revealed that the Multimodal Approach had a positive effect when teaching English idioms to EFL students. The findings also demonstrated that the activities used during the classes were dynamic and that broke the traditional practices used to teach these non-formal words. Also, it is necessary to consider modern techniques that allow students learn in different styles and mostly that motivate them learn contents in an active way. Therefore, based on the obtained results, it was concluded that the Multimodal Approach could be considered as an effective way to teach and learn English idioms within EFL contexts.
\end{abstract}

Keywords: multimodal approach, effects, English idioms, EFL

DOI: $10.7176 / \mathrm{JEP} / 12-24-03$

Publication date:August $31^{\text {st }} 2021$

\section{Introduction}

Nowadays, the integration of technology in the $21^{\text {st }}$ century has changed the manner in which people think, work and live; furthermore, it is also considered a relevant point in many areas including education (Ghavifekr \& Athirah, 2015; Grabe \& Grabe, 2007). Since technology plays an important role within the educational system, it is suggested that schools and education institutions take into consideration the integration of ICT within their curriculum in order to encourage learners to immerse themselves in a 'knowledge society' (Ghavifekr \& Athirah, 2015). Albirini (2006) points out that the objective of ICT integration relies on improving and incrementing the quality, accessibility, and cost-efficiency of learners' instruction. Furthermore, the role and integration of technology is relevant and thanks to it education has become more interactive and dynamic rather than passive and reactive (Raja \& Nagasubrami, 2018).

The impact promoted by ICT has also increased the role of participation of the students in the classroom (Shelly, Gunter, \& Gunter, 2012). Sianturi (2017) mentions that learners used to participated and learn by listening to the teacher's lectures, by raising their hands to answer questions, or working in written tasks individually. In fact, students were less participative and more passive rather than active learners, which basically, limited their capacities to explore and expand their knowledge; nonetheless, this has changed because of the new technological resources that exist within the classrooms; therefore, the inclusion of technology in the classroom encourages a learner to be active when learning and communicating (Sianturi, 2017).

Since technology can be applied in different teaching backgrounds, it also gives the opportunity to teach contents like idioms that have been taught in different studies through the implementation of the multimodal approach. As mentioned in Kress and Van (2006) the multimodal approach is mainly focused in the combination of text, audio, and image as individual modes and that the combination of these modes could be combined to create meaning, encouraging, cooperation, and learning in a classroom. Since the multimodal approach offers a variety of ways of teaching by combining the content and technology, some researchers like Amos and Abas (2021), Freyn and Gross (2017), Tabatabaei and Gahroei (2011), Yang and Xie (2013), Tafazoli and Kargozari (2012), and Thiruvengadam (2016) have applied it to teach idioms using a series of technological resources. In their studies, they have proved that the multimodal approach has caused a positive impact in the teaching and learning of idioms in the classroom. Therefore, the use of the multimodal approach might be possible when teaching idioms to university students since it combines different designs or modes such as linguistic, visual, audio, gestural, and spatial that may allow students to learn and acquire idioms by combining different designs.

Considering the aforementioned studies and points, this research aims to portray the importance of teaching idioms through the use of the multimodal approach in A2 EFL university learners. For this purpose the following research question was established:

1. To what extent does the Multimodal Approach enhance the learning and use of idioms in EFL university students? 


\section{Literature Review}

\subsection{Multiliteracies: a Brief Background}

In the last years, educators, researchers, policymakers and other educational stakeholders have been interested in the need of developing new literacy practices that help to reduce traditional pedagogical and traditional literacy practices (Rajendram, 2015). By traditional literacy Moats (2000) refers to it as the skill to apply the written language actively or passively or to read, write, spell, listen and speak in active or passive way. In order to reduce traditional pedagogical practices in literacy, Cazden et al. (1996), a group of 10 educational researchers known as the London Group that appeared in 1996, proposed a new pedagogy concept of Multiliteracies which goes from a traditional understanding of literacy to a modern pedagogy called 'multiplicity of discourses' better known as Multiliteracies. This pedagogy is established in two relevant ideas: the first one, expanding variety of text forms related to the expansion of mass media, multimedia and the Internet, and the second one, increasing importance of linguistic and cultural diversity (Rajendram, 2015). Besides, the Multiliteracies Pedagogy is focused on promoting the educational acts or information forms of encountering, conceptualizing, analyzing and applying (Kalantzis \& Cope, 2005).

On the other hand, Kalantzis and Cope (2008) mention that this type of pedagogy recognizes that not every learner brings to their learning the same life-world experiences, language skills, socio-cultural resources and interests, and it supports a multimodal approach where learners move between the linguistic, visual, auditory, gestural, and spatial modes of meaning and learning. Additionally, Rowsell, Kosnik, and Beck (2008) point out that the concept of multiliteracies proposed by Cazden et al. (1996) see literacy as continuous, complementary, and modifying established literacy teaching and learning, rather than replacing traditional practice. Consequently, the perspective of Cazden et al. (1996) regarding traditional literacy, relying on printed text was seen as limited and restrictive; they perceive the necessity to spread new ways for learners to engage in a variety of text forms related to information and multimedia technologies. Therefore, Cazden et al. (1996) point out that multiliteracies develop a new type of pedagogy in which different modes of meaning are interactive representational resources that combine the textual with the visual, the audio, the spatial, and the behavioral, among other modes.

In other words, the authors' goal basically consider that the implementation of their concept regarding multiliteracies is to overcome the limitation of common or traditional approaches of literacy. To do so, it is necessary to include Multimodalities that encourage students to become active learners rather than passive ones, and at the same time, incorporate ways that allow students to learn new concepts from different sources such as visuals, audios, or any kind of multimodal contexts.

\subsection{Multimodal Learning Approach}

According to Sankey, Birch, and Gardiner (2010) multimodal learning environments make it possible to present instructional elements by means of more than one sensory mode (visual, auditory, written). The multimodal approach arises as the necessity to create a relationship of six significant modes, channels used in a classical classroom situation, proposed by Cazden et al. (1996), which are Linguistic Design, Visual Design, Audio Design, Gestural Design, Spatial Design and the Multimodal Design that combines two or more modes of Design. The Multimodal mode is considered the most important out of the six modes as it connects all the other modes creating a significant dynamic connection. Furthermore, each mode design plays an important role when connected to the multimodal approach, as they are resources that permit the design of meanings.

The application of the Multimodal Approach is an efficient way to present the written texts in a more visual dynamic concept (Cazden et al., 1996). Chen and Fu (2003), Moreno and Mayer (2007), and Zywno (2003) agree that the materials that are showed by means of different modes might make students perceive that it is easy to learn and improve attention as well as their learning performance, especially for those who are lowerachieving learners. Mayer (2003) affirms that learners gain more from combining words and pictures than from words only recognized as the 'multimedia effect.' Besides, Fadel (2008) stated that learners that are taught through multimodal designs, on average, have better performance than those who learn by traditional approaches that incorporate one mode only.

\subsection{Defining idioms}

The Oxford Advanced Learner's Dictionary (2015) defines an idiom as a set of words whose meaning is not the same word by word, but the whole phrase. Zarei (2016) explains that the complete meaning of an idiomatic expression is based on the sum of the whole phrase. Additionally, Sinclair (1991) states that an idiom is the combination of two or more words that are joined to produce a certain meaning or effect in speech or writing. In other words, an idiom is a sum of words whose meaning cannot be literally deduced by translating each one of its parts, but the whole phrase, and whose figurative meaning is recognized by common use (Maisa \& Karunakaran, 2013).

Baştuğ and Salihagić (2014) claim that as idioms exist in any language, they are also a tool used to communicate in all forms and styles of language and that these expressions are applied by native speakers. The 
same authors agree on the idea that idioms create connections among people by promoting a vision of the language used in a culture. In the same light, Yagiz and Izadpanah (2013) establish an important idea in relation to idioms and culture; they mention that idioms seem to be natural decoders of customs, cultural beliefs, societies and norms. Finally, according to the McCarthy (2010), idioms are a colorful and amazing aspect of any language, as they are applied in all its forms, informal and formal, spoken and written. Learners' language skills might improve if they comprehend and make and effective use of idioms.

2.3.1 Common Types of Idioms

Having several possibilities of idioms that are considered important by different authors, only some types have been selected to show the types of idioms that exist. Therefore, idioms taken from The EF English live guide to: English Idioms written by the EF Company (2016) have been selected to exemplify common types of idioms:

a) Idioms referring to the natural world

b) Idioms referring to parts of the body

c) Idioms to talk about feelings or emotions

d) Idioms to describe a bad mood

e) Idioms to express understanding

f) Idioms about having fun

\section{Methodology}

\subsection{Setting and Participants}

This quantitative study was carried out in the city of Cuenca, Ecuador at the Language Department of Universidad de Cuenca, and had a quasi-experimental design. The study involved a group of 24 EFL Ecuadorian students whose English level was A2; 13 men 11 women composed the group of students. Their age range was from 19 to 28; with an average age of 22.91 ( $\mathrm{DE}=2.52)$ and a student of 42 . All participants voluntary agreed to take part of study. The participants were majoring in different areas: Math, Social Community, Law, Journalism, Physical Education, Philosophy, and Engineering. All the participants spoke Spanish as their mother tongue. They received 6 hours of instruction on two hours per class three times a week. The treatment was applied during the class hours, and one online hour for activities was assigned to the participants. They used in the bookselected pages from the book English Idioms in Use, websites, apps, and worksheets prepared by the researchers.

\subsection{Instruments and Materials}

\subsubsection{Pretest and Posttest}

The pretest and posttest were designed based on the entry test presented on the Book English Idioms in Use. These instruments were used to analyze the level of knowledge and understanding that learners had regarding English idioms before and after the treatment. These tests included combining questions, completion questions, rewriting questions, and matching questions. Both had the same level of difficulty.

\subsection{Materials}

\subsubsection{Book Used for Teaching English Idioms}

The book selected for teaching idioms was English Idioms in used (2017) second edition by Michael McCarthy and Felicity O'Dell. For this study, only 58 idioms were taken into consideration divided in 5 categories: 1: Conversational responses idioms 2: Money, work and Effort idioms; 3: Social status, human relationships, probability, and luck idioms: Clothes, colors, and food idioms; and 5: Proverbs. The researcher selected these categories as they have some similar use in participants' L1.

3.3.2 Websites and Apps

In order to apply the Multimodal approach, some websites and apps were used to teach each idiom category. The Quizlet platform was the core of the practice for teaching and using idioms; WhatsApp was used by students to interact in English with their classmates by making comments of their favorite idioms learned during and after the lessons; Canva Website allowed students to design pictures that represented their favorite idioms learned after the sessions; the Code Reader App was a means to ask students to de-codify the meaning of idioms by using paper codes distributed around the computer lab or corridors of the University. To do so, the Code Reader App was installed on each learner's cell phone. This app allowed students to practice, review, and study the meaning of idioms; and Kahoot Webs allowed students to compete in groups or individually regarding idioms sentence completion, selection of correct English idioms and its definition, and selection of the appropriate image that represented the idiom shown on the screen. This website contributed a lot in the feedback of idioms as students liked to compete and practice what they learned.

3.3.3 Worksheets

In addition to the virtual resources, worksheets were used to make students practice idioms by means of matching activities, completion activities, short conversation activities, and writing activities (simple sentences) that contained idioms used in context. These worksheets also helped students to reinforce the idioms learned in 
classes.

\subsection{Treatment}

A multimodal course was designed by the researcher in order to teach idioms by means of websites, apps, listening activities, visuals, images, virtual games, and worksheets since these activities line to what is proposed by the multimodal approach. To do so, the researcher made use of a Computer Lab; each learner worked in one computer, and sometimes in groups or pairs. The idioms course lasted 32 hours divided in: 24 in-class hours and eight individual study hours. These eight hours were controlled and assessed by the researcher using the Quizlet website. In order to develop a coherent study and collect the necessary data, the research was divided in three stages: before the intervention, during the intervention, and after the intervention.

3.4.1 Before the intervention

Before starting the intervention, the researcher held a meeting with the participants in order to provide them with information about the study. Once the information shared with the students was clear, the researcher gave each one of them the informed consent form so that they could agree or not to be part of the study. All of them signed and confirmed their decision to participate. On a second part of the study, the students took the pretest. The students received clear instructions about the purpose of the test. After this instrument was applied, the intervention began based on a fixed schedule.

3.4.2 During the intervention

As it was proposed at the beginning of this study, 24 hours were carried out in the classroom and eight online (at home). Besides, all the idioms studied were combined with the topics and content studied in the syllabus of English. During the class sessions, the participants were exposed to different activities that matched the Multimodal Approach requirements and that had connection to the theories presented in the Literature Review. The idioms used for this study were carefully selected from the book selected. Some activities used to teach these idioms were based on technological resources, apps, and websites that helped students learn idioms in an interactive way.

At the beginning of each lesson, the instructor introduced the idioms in context through a series of images and situations. Students discussed the possible meanings briefly. After the presentation of idioms, the teacher elicited students' attention by means of dynamic activities and multimodal resources that encouraged students' participation. At the end of each Idiom Unit, an online test was given to the participants in order to monitor their understanding on idioms.

3.4.3 After the intervention

After five units of English Idioms were taught, a posttest was applied to examine whether the participants after the Multimodal Approach treatment had improved or not their level of knowledge of English Idioms.

\section{Results}

\subsection{Data Analysis}

The quantitative data obtained from the pretest and posttest was analyzed through descriptive statistics. All the information obtained from the analysis was organized using graphs in order to show relationships and tendencies. For the presentation of the results obtained from the statistics analysis, measures of central tendency and dispersion were applied. Also, the results were quantified through absolute frequencies in order to have a better interpretation of the data. The data processing was done with a statistical program SPSS 25 , and the tables and graphs were edited in Excel 2016. The behavior of the data turned out to be no normal, as confirmed by the test Shapiro Wilk of normality $(\mathrm{p}>.05)$ consequently a nonparametric test of Wilcoxon was employed. Finally, to compare the responses from the pretest and the posttest, the decisions were taken with a significance of $5 \%$ ( $p<$. 05).

\subsection{Findings in response to the research question}

The findings of the current study respond to the research question that sought to investigate the extent of enhancement that the Multimodal Approach had in the learning and use of idioms in EFL students. The general knowledge regarding idioms was evaluated based on five categories with a score of 30 points in total. Before the intervention, the scores were between four and 24 with a mean of $10.96(\mathrm{DE}=4.64)$; in figure 1 it can be observed a tendency to low scores, which reflects that the majority of students only reached the third part $(30 \%)$ of the highest score.

Before the intervention, low average scores were obtained, below to the median of each category and with high dispersions. However, after the intervention the scores obtained by the students were very close to the upper limit (30) in all the categories evaluated, and with low dispersions implying a similarity of behavior. Table 1 shows in detail the significant improvements in idiom knowledge $(\mathrm{p}<.05)$ between 2.50 and 4.66 points.

After the intervention, the results significantly improved as seen in figure 2. In the category "Social Status, human relationships, probability and luck idioms" it can be observed that all the participants improved their 
scores; while in the category "Clothes colors, and food idioms" only 19 participants presented ratings improvements and five participants without changes. In the rest of the categories almost all the participants $(n=23)$ improved considerably.

The final scores obtained with the sum of each of the sections ranged from 18 to 30 with a mean of 28.21 (SD-2.8) involving a scope of $93.3 \%$ of knowledge in idioms which indicates a high performance score and improvement in contrast to the pretest results in which the majority of students only reached the third part (30\%) of the highest score.

\section{Discussion}

The results obtained in this study are in line with results presented by Freyn and Gross (2017), Tabatabaei and Gahroei (2011), Yang and Ying (2013), and Tafazoli and Kargozari (2012) who explain that using different resources, related to the multimodal approach, allow students to learn and acquire idioms specially if technological tools and visuals are used to teach these non- formal words. Freyn and Gross (2018) explain that by means of technology induced interactions; multimodality provides resources and opportunities that challenge the traditional forms of teaching. They add that it is necessary that teachers adopt more multimodal activities in the class in order to give students more opportunities for understanding idioms and improving their idiomatic proficiency.

In Tabatabaei and Gahroei's (2011) study, the authors mentioned that the effectiveness of using movie clips and film that contain idioms created a positive attitude and effect in learners. This visual approach not only allowed students to explore idioms in a more interactive way, but also to identify the significant effects it had on idiom learning. In Yang and Ying's (2013) research, the results showed that the textual and visual illustrations of the idioms created by the learners facilitated their learning of the idioms. In this case, a mobile way of learning idioms was applied, and the results were also effective. In their study, the researchers suggest that the implementation and combination of technological tools enhance students to have a better performance in idioms. In fact, this result is similar to the ones obtained in this study in which the participants went from bottom to top. This was possible because the researchers used different tools that allowed participants to increase their vocabulary through different activities that promoted their capacity to acquire and understand idioms effectively. So, as mentioned by Yang and Ying (2013) textual and visual representations of the idioms make students learn them effectively. Particularly, Tafazoli and Kargozari (2012) also agree on the fact that certain technological tools can be adapted to teach idioms. In their study, the researchers applied mobile phones on learning idioms and suggested that this type of activities encourages students to learn more about idioms while interacting with technology. At the same time, Amos and Abas (2021) add that the application of the multimodal approach, through technology induced interactions, allows the use of resources that challenge traditional ways of teaching.

In short, the results and the findings of this study match with what has been previously said, that creating different ways to teach and learn idioms allow students to have a better connection and understanding of the topic. This is why the results presented in this research show that the multimodal approach is an effective way to enhance in learning and using of idioms, and that it also generates a significant impact on students.

\section{Conclusions}

This study sought to investigate the effect of using the multimodal approach toward teaching English idioms to a group of 24 A2 EFL Ecuadorian students. The results indicated that the Multimodal Approach was effective when learning and teaching English idioms. The participants improved their capacity to understand, learn, and use in different contexts. Additionally, the results of this study confirmed the findings of previews research on teaching idioms through the Multimodal Approach. The quantitative results demonstrated that students get more interest when learning through different virtual tools and that the combination of written material and technology increases the interest of learners when learning new topics, in this case idioms. Therefore, the written contents that were the part of the material given to the students were combined with some other resources like apps, websites, and platforms that allowed students to have a better connection to learn idioms, and of course to feel motivated, and to go beyond traditional approaches like memorization. On the other hand, learners demonstrated that the activities used during the classes were dynamic and that broke the traditional practices used to teach these non-formal words. Bearing this in mind, it can be inferred that students learn better when the subject method is not passive, but rather active through activities that encourage and motivate them to learn. Therefore, it is necessary to consider modern techniques that allow students learn in different styles and mostly that motivate them learn contents in an active way. Finally, one future research direction is to focus on the perceptions of the multimodal approach to learn idioms; this would complement the results obtained on this study.

\section{References}

Albirini, A. (2006). Teachers' attitudes toward information and communication technologies: The case of Syrian 
EFL teachers. Computers \& Education, 47(4), 373-398.

Amos, T., Abas, I. (2021). Idiom Comprehension using Multimodal Teaching Approach among Zanzibar University Students. Advances in Language and Literary Studies, 12(3), 83-89.

Cazden, C. et al. (1996). A pedagogy of multiliteracies: designing social futures. Harvard Edu-cational Review, $66(1), 60-92$

Chen, G., \& Fu, X. (2003). Effects of multimodal information on learning performance and judgment of learning. Journal of Educational Computing Research, 29(3), 349-362.

EF Company. (2016). The EF English live guide to: English Idioms. EF English Live:Language \& Lifestyle Guides, 2-23.

Fadel, C. (2008). Multimodal Learning Through Media: What the Research Says. San Jose, CA: Cisco Systems.

Freyn, A.,\& Gross, S. (2017). An Empirical Study of Ecuadorian University EFL Learners' Comprehension of English Idioms Using a Multimodal Teaching Approach. Theory and Practice in Language Studies. 7 (11), 984-989.

Ghavifekr, S., \& Athirah, W. (2015). Teaching and Learning with Technology: Effectiveness of ICT Integration in Schools. International Journal of Research in Education and Science (IJRES), 1, 175-191.

Grabe, M., \& Grabe, C. (2007). Integrating technology for meaningful learning (5th ed.). Boston, MA:Houghton Mifflin.

Kalantzis, M., \& Cope, B. (2005). Learning by design. Victorian Schools Innovation Commission \& Common Ground Publishing, Melbourne, Vic.

Kalantzis, M., \& Cope, B. (2008). Digital communications, multimodality and diversity: Towards a pedagogy of multiliteracies. Scientia Paedagogica Experimentalis, XLV(1), 15-50

Kress, G. \& Van, T. (2006). Reading Images. The Grammar of Visual Design. Abingdon, Newyork: Routledge.

Mayer, R. E. (2003). Elements of a science of e-learning. Journal of Educational Computing Research, 29 (3), 297-313.

Maisa, S., \& Karunakaran, T. (2013). Idioms and Importance of Teaching Idioms to ESL Students: A Study on Teacher Beliefs. Asian Journal of Humanities and Social Sciences (AJHSS), 1, $1-13$.

McCarthy, M. (2010). Cambridge Idioms Dictionary. (2nd ed.), Cambridge: Cambridge University Press.

Moats, L. (2000). Speech to Print: Language Essentials for Teachers. Paul H. Brookes, Baltimore.

Moreno, R., \& Mayer, R. (2007). Interactive multimodal learning environments. Educational Psychological Review, 19, 309-326.

Hornby, A. S., Ashby, M., \& Wehmeier, S. (2015). Oxford advanced dictionary. Oxford: Oxford University Press.

Raja, R., \& C. Nagasubramani, P. (2018). Impact of modern technology in education. Journal of Applied and Advanced Research, 33-35.

Rajendram, S. (2015). Potentials of the Multiliteracies Pedagogy for Teaching English Language Learners (ELLs): A Review of the Literature. Critical Intersections in Education, 3, 1-18.

Rowsell, J., Kosnik, C., \& Beck, C. (2008). Fostering multiliteracies pedagogy through preservice teacher education. Teaching Education, 19 (2), 109-122.

Shelly, G., Gunter,G., \& Gunter,R.(2012). Teachers Discovering Computers: Integrating Technology in a Connected World. Boston, MA.

Sianturi, S. (2017). Informatics Technology in the Classroom. Informatics Technology in the Classroom, 3,1-3.

Sinclair, John. (1991). Corpus, Concordance, Collocation. Oxford: Oxford University Press.

Tabatabaei,O.,\&Gahroei,F.(2011). The Contribution of Movie Clips to Idiom Learning Improvement of Iranian EFL Learners. Theory and Practice in Language Studies, 1 (2), 990-1000.

Tabatabaei, Omid., \& Gahroei, Firooz. (2011). The Contribution of Movie Clips to Idiom Learning Improvement of Iranian EFL Learners. Theory and Practice in Language Studies, 1 (2), 990-1000.

Tafazoli, D., \& Kargozari, H. (2012). Idiom on the move: Mobile a ubiquitous technology for learning idioms, The 6th International Technology, Education and Development Conference (INTED2012), presented at International Association of Technology, Education \& Development, Valencia, Spain.

Thiruvengadam, P. (2016). Using Games as a Tool in Teaching Idioms. Emerging Trends in Digital Era through Educational Technology, 295-297.

Yang, C \& Xie, Y. (2013). Learning chinese idioms through ipads. Language Learning and Technology, 17,1222.

Yagiz, O., \& Izadpanah, S. (2013). Language, culture, idioms, and their relationship with the foreign language. Journal of Language Teaching and Research, 4 (5), 953- 957.

Zarei, A. (2016). Etymology, Contextual pragmatic clues, and Lexical awareness.

Zywno, M. S. (2003). A contribution to validation of score meaning for Felder-Solomon 'es Index of Learning styles. Proceedings of American Society for Engineering Education Conference and Exposition. 


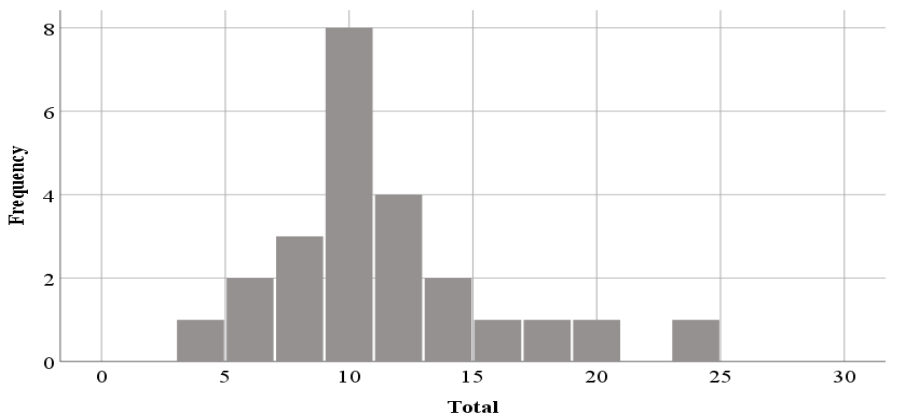

Figure 1. Scores Distribution

Clothes, Colors, and Food Idioms

Life and Experience: Proverbs.

Money, Work, and Effort

Conversational-Responses Idioms

Social status, human relationships, probability and luck Idioms

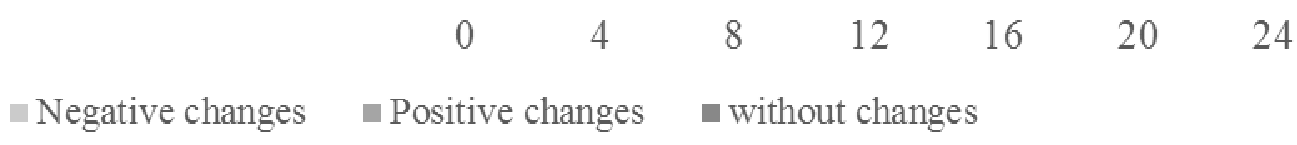

Figure 2. Changes between the pretest and posttest

Table 1. Pretest and Posttest results of idioms in an A2 EFL classroom

\begin{tabular}{llllllllllll}
\hline \multicolumn{1}{c}{ Pretest } & \multicolumn{1}{c}{ Posttest } & \multicolumn{1}{c}{ Difference } & p \\
\hline Social status, human relationships, & 0 & 3 & 1,50 & 1,02 & 4 & 6 & 5,71 & 0,55 & 4.21 & & $.000^{*}$ \\
probability and luck Idioms (/6) & & & & & & & & & & \\
Conversational-Responses Idioms (/6) & 0 & 5 & 2,75 & 1,23 & 1 & 6 & 5,63 & 1,14 & 2.88 & & $.000^{*}$ \\
Money, Work, and Effort (/8) & 0 & 5 & 2,67 & 1,47 & 2 & 8 & 7,33 & 1,52 & 4.66 & $.000^{*}$ \\
Life and Experience: Proverbs (/5) & 0 & 4 & 1,42 & 1,28 & 1 & 5 & 4,46 & 1,06 & 3.04 & $.000^{*}$ \\
Clothes, Colors, and Food Idioms (/5) & 0 & 5 & 2,50 & 1,50 & 5 & 5 & 5,00 & 0,00 & 2.50 & $.000^{*}$ \\
\hline
\end{tabular}

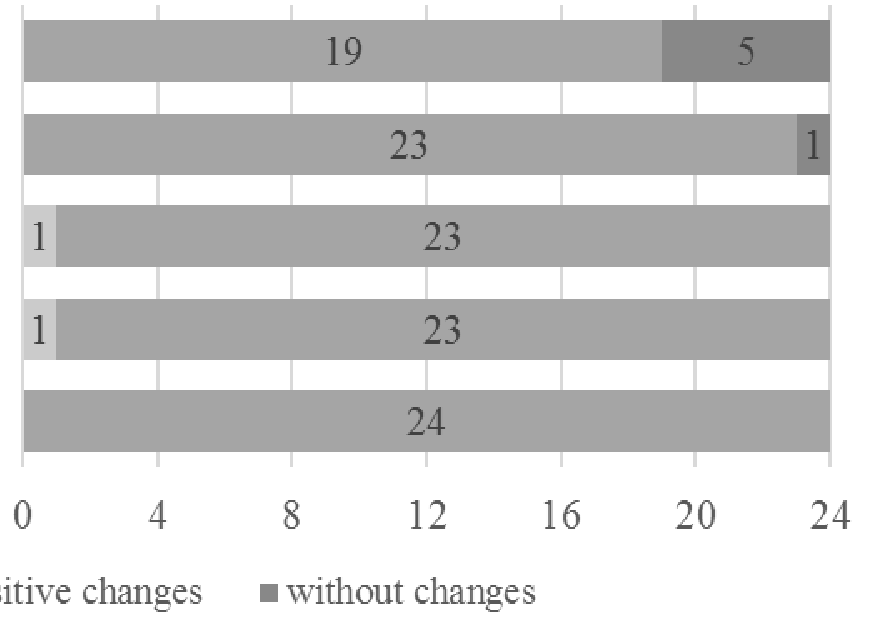

\section{3}

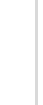

